\title{
¿Descentralización o gobernanza? El agua, la institucionalización y la política en la cuenca alta del Río Cauca, Colombia*
}

\author{
Raúl Cortés Landázury (Colombia)** \\ Alejandra Riascos López (Colombia)*** \\ Willian Idrobo Salazar (Colombia) ${ }^{* * * *}$
}

\section{Resumen}

En una época en que se han quebrantado los alcances y la capacidad del Estado para suplir demandas sociales y ambientales — como el suministro del agua-, la gobernanza policéntrica es una alternativa ante la crisis de legitimidad del sector público, en parte agenciada por las restricciones fiscales y una iniciativa privada que amenaza acaparar los recursos naturales, profundizando los problemas redistributivos. La apuesta de esta investigación apunta a rastrear la degradación hídrica a través de sus relaciones con el proceso de institucionalización de reglas formales y su posterior ensamble en redes de gobernanza policéntrica. Es así como esta pudo integrar una serie de métodos que, bajo la orientación abstracta de un modelo presión-Estado-respuesta, abarca elementos de corte cualitativo — como el análisis documental - y cuantitativos —como el análisis econométrico y el estudio de grafos, muy cercano al desarrollo de la topología-. Esta investigación, pudo comprobar que los ligeros niveles de organización social afectaron positivamente los resultados en términos de reducción del efecto degradatorio sobre la calidad del agua.

\footnotetext{
* El artículo hace parte de los proyectos de investigación de la Universidad del Cauca De las dinámicas institucionales al desarrollo sostenible regional: la economía política del agua y la degradación en la cuenca Alta del rio Cauca, 2012-2013; y Acción colectiva, cohesión social y asocianismo étnico en el departamento del Cauca, 2016-2017.

${ }^{* *}$ Economista. Especialista en Gestión Ambiental. Magíster en Estudios Políticos. Doctor en Economía de los Recursos Naturales y Desarrollo Sostenible. Profesor titular del Departamento de Ciencias Económicas, miembro del grupo de investigación Desarrollo y Política Públicas Polinomía y mentor del semillero de investigación Panarquía, Universidad del Cauca, Colombia. Correo electrónico: rcortes@unicauca.edu.co - Orcid: https://orcid.org/0000-0003-2923-0523

*** Economista. Miembro del semillero de investigación Economía de las Desigualdades, grupo de investigación Pensamiento Económico, Sociedad y Cultura, y coordinadora del semillero Panarquía, grupo de investigación Desarrollo y Políticas Públicas Polinomía, Universidad del Cauca, Colombia. Correo electrónico: priascos@unicauca.edu.co - Orcid: https://orcid.org/0000-0002-2048-065X

**** Economista. Miembro del semillero de investigación Panarquía, grupo de investigación Desarrollo y Políticas Públicas Polinomía, Universidad del Cauca, Colombia. Correo electrónico: willianidrobo@ unicauca.edu.co - Orcid: https://orcid.org/0000-0003-3251-1238
} 


\title{
Palabras clave
}

Instituciones Políticas; Políticas Públicas; Gobernanza; Gestión de Recursos Naturales; Descentralización; Colombia.

Fecha de recepción: octubre de 2018

- $\quad$ Fecha de aprobación: marzo de 2019

\section{Cómo citar este artículo}

Cortés Landázury, Raúl; Riascos López, Alejandra e Idrobo Salazar, Willian. (2019). ¿Descentralización o gobernanza? El agua, la institucionalización y la política en la cuenca alta del Río Cauca, Colombia. Estudios Políticos (Universidad de Antioquia), 55, pp. 205-223. http://doi.org/10.17533/udea.espo.n55a10

\section{Decentralization or Governance? Water, Institutionalization and Politics in the High Basin of the Cauca River (Colombia)}

\begin{abstract}
At a time when the scope and capacity of the State to meet social and environmental demands, such as water supply, have been lost, polycentric governance

[206] is an alternative to the crisis of legitimacy of the public sector, partly driven by fiscal restrictions and a private initiative that threatens to monopolize natural resources, deepening redistributive problems. The aim of this research is to track the water degradation through its relations with the process of institutionalization of formal rules and their subsequent assembly into networks of polycentric governance. The study integrates a series of methods that, under the orientation of a pressure-stateresponse model, includes qualitative elements such as documentary analysis, as well as quantitative analysis such as econometric analysis and the study of graphs, very close to the development of topology. This study verifies that the slight levels of social organization positively affected the results in terms of reducing the degradation effect on water quality.
\end{abstract}

\section{Keywords}

Political Institutions; Public Politics; Governance; Natural Resources Management; Decentralization; Colombia. 
¿Descentralización o gobernanza? El agua, la institucionalización y la política...

\section{Introducción}

Frente al interés de evaluar los efectos de la reforma ambiental de 1991 (Foro Nacional Ambiental, s. a.). A través de la descentralización y su sistema de gobernanza, el tema de la degradación hídrica en la cuenca alta del río Cauca (1990-2011) sirve de pretexto para discutir el desenvolvimiento de la acción colectiva frente al cambio institucional e incluso examinar el papel de la sociedad civil como promotora y dinamizadora de nuevas demandas sociales y arreglos institucionales multinivel, que para algunos autores como Ronald Inglehart y Paul Abramson (1994) ha venido a hacer parte de las demandas posmaterialistas. La hipótesis aquí presentada resultaría esperanzadora, toda vez que la sospecha de que ante el avance privatizador del mercado y las limitaciones fiscales y burocráticas del Estado, en una época de expansión y profundización de las llamadas reformas estructurales — década de 1990—, la arremetida de movilización social podría contrarrestar la amenaza devastadora de los recursos naturales y especialmente aquellos de «libre acceso». En efecto, sería mediante la acción protagónica de las organizaciones civiles, tal como James O'Connor (2001) alude a los llamados «nuevos guardias rojosverdes», que se revertiría la tendencia a recrear la denominada «tragedia de los comunes» y su posterior efecto macroeconómico, designado como «maldición de los recursos naturales» (Auty, 1993). ${ }^{1}$

Sin embargo, en medio del asunto estarían instituciones ancladas en la historia, tales como la herencia colonial y hacendaria, las cuales, aparte de señalizar la estructura de usos del suelo y la dinámica del aprovechamiento del agua, pondrían la impronta a las formas en que se toman las decisiones de gestión ambiental, incluso, modificando los designios de una administración pública que bajo el nuevo modelo de desarrollo, orientado a resultados eficientes, aspiraba ser más plural y posburocrática. Asimismo, la Ley 99 de 1993, mediante su despliegue técnico-modernizador, busca combatir el fenómeno degradatorio mediante la aplicación de instrumentos económicos - costo-efectivos - como los impuestos pigouvianos ${ }^{2} y$, de paso, disminuir

\footnotetext{
${ }^{1}$ La maldición de los recursos naturales alude a que países y regiones con abundancia de recursos naturales tienden a tener un menor crecimiento económico y, sobre todo, altos grados de inequidad frente a países con menos recursos de este tipo. En buena parte, el asunto se explica por las diferencias en materia de calidad institucional.

${ }^{2}$ Se establecen para corregir los efectos de una externalidad negativa, es decir, son impuestos que pagan las empresas por generar externalidades como la emisión de gases, humo, olores fuertes, entre otros (Mochón, 2006).
} 
la fuerza coercitiva de las herramientas de «comando y control» para ampliar el espacio de la participación comunitaria.

En la investigación se analizaron, por medio de instrumentos económicos, la tasa retributiva frente al problema de la contaminación hídrica y las fracturas institucionales identificadas en el Documento del Consejo Nacional de Política Económica y Social (Conpes) del río Cauca (3624 del 20 de noviembre de 2009), las cuales sobresalen en medio de problemas estructurales como la brecha política entre las autoridades del sector, los grupos indígenas, las comunidades afro y las campesinas; asimismo, la descoordinación propia de una arquitectura organizacional que se reparte en el plano político administrativo, lo correspondiente a dinámicas socioecológicas ajustadas a las características biofísicas y las formas consuetudinarias de apropiación del territorio, al igual que los desencuentros en materia de articulación de iniciativas frente al cuidado del río. Empero, este trabajo pudo constatar por la vía econométrica que en el periodo analizado los ligeros niveles de organización social afectaron de manera positiva los resultados en términos de reducción del efecto degradatorio sobre la calidad del agua.

No obstante, al revisar la forma de tales relacionamientos pervivió un

tipo de organización o sistema de gobernanza neocorporativa en muchos casos anclados al statu quo. A lo mejor, el propio modelo de descentralización iniciado con la Constitución Política de 1991 no tuvo el vigor político suficiente para lograr un empalme efectivo entre la idea de delegar y transferir autonomía y la propia lógica de los ecosistemas en afinidad con las prácticas comunitarias que viven y sienten el territorio, y menos aún, lograr una amplia participación constructora de nuevos anidamientos sociales y ciudadanías complementarias, aunque sus referentes fueran diferenciados.

Quizás la propia dinámica institucional, centrada en el rol protagónico de élites económicas o políticas, lo desvió del camino de tener una especie de autonomía regional que en cada entidad desconcentrara pero no descentralizara. De ahí que mediante el análisis de redes se evidencia cómo la acción social participativa trae resultados positivos para el manejo de este gran afluente. Más allá de toda esta discusión, lo que está en juego es el nivel de legitimidad del sistema y su capacidad para responder a la escasez del agua de forma eficiente, eficaz, democrática e inclusiva hacia al futuro. 
¿Descentralización o gobernanza? El agua, la institucionalización y la política...

\section{La nueva perspectiva oficial del suministro de agua regional}

Históricamente, la política de agua potable y saneamiento básico en Colombia hizo énfasis en la cobertura de redes descuidando la articulación con la oferta hídrica. De esta manera, en el afán de atacar la problemática del suministro de calidad, el Gobierno puso sus ojos en el acoplamiento de la oferta mediante los planes departamentales del agua (PDA).

Hacia 2010, la Organización de las Naciones Unidas (ONU) declaró el agua potable y el saneamiento como derecho humano, al unirse a la iniciativa que impulsó Bolivia sobre la dotación de un líquido limpio y seguro para todos los ciudadanos (Resolución 64/292, 2010). Pero paralelamente a las iniciativas oficiales por la consolidación del sector, se desató un intenso debate alrededor de las bondades de la intervención del Estado, llamando al «orden social»y «la modernización sectorial» con aporte del mercado (Contraloría, 2011), sobre todo por las características del bien a suministrar o a comercializar, toda vez que se trata de un bien de carácter nacional, de uso público, esencial y preferente, y cuyo usufructo y explotación compromete el desarrollo sostenible.

Efectivamente, dando curso a la Ley 142 de 1994, el Documento Conpes 3383 de 2005 da impulso a esquemas regionales de prestación de servicios para que los departamentos desempeñen un papel central de articulación y optimización de fuentes financieras. Pero en marzo de 2007, mediante el Documento Conpes 3463, se ampliaron los objetivos, concentrándose en uno fundamental: regionalizar la provisión de los servicios de agua potable y saneamiento básico a través de la concentración en grandes operadores especializados con capacidad técnica y operativa para mejorar la cobertura, eficiencia y calidad de la prestación, con financiación a cargo de los municipios beneficiados, de los departamentos y la Nación. Puesto en términos teóricos, se buscó desplegar el modelo de federalismo fiscal y la descentralización, creando grandes monopolios naturales en procura del aprovechamiento de economías de escala y el manejo empresarial de los servicios de acueducto y alcantarillado. ${ }^{3}$ Es más, con la Ley 1151 de 2007

\footnotetext{
${ }^{3}$ Todo esto intenta retrotraer los filamentos de la norma constitucional, desplegando numerales como el Artículo 298, el cual alude a la autonomía para la administración de los asuntos seccionales y la planificación y promoción del desarrollo económico y social dentro de su territorio.
} 
—Plan de Desarrollo 2006-2010 — se planeó atacar deficiencias significativas en la distribución y aplicación de los recursos del Sistema General de Participaciones — transferencias de la Nación—, anomalías en la focalización de subsidios a la demanda e inadecuada disposición final de residuos sólidos. En consecuencia, los departamentos serían la instancia de coordinación con el Gobierno nacional en la implementación de los planes en procura del mejoramiento de los indicadores de cobertura y calidad.

No obstante, tanto en este caso como en el que lo precedió, con la reforma ambiental de la década de 1990, la excesiva atención al modelo de descentralización con eficiencia descuidó los aspectos institucionales y de gobernanza del agua. Tanto que trata de asimilar sistemas comunitarios de administración del líquido al gran ente de ejecución y administración regional, desatendiendo las fracturas protuberantes de coordinación intra e interdepartamental que abarcan tanto a organismos públicos como a privados. Quizá por ello el desencuentro entre la oferta y la demanda institucional, el cual pasa por cuestiones como un mal análisis de redes de gobernanza, ha hecho que $82,6 \%$ de los proyectos evidenciara retraso en el diseño, contratación y ejecución de las obras requeridas para el aumento de las coberturas y el mejoramiento de la prestación de los servicios (Contraloría, 2011). Esto augura la inviabilidad a largo plazo del modelo gubernamental implícito.

Incluso cuando no existe ningún plan acabado para una buena gobernanza del agua, se pueden señalar algunas pautas. Para empezar, el primer elemento a enfrentar es la presión que deviene de los ritmos de producción nacional y regional, pero que además depende del modelo de desarrollo implementado a finales del siglo xx. En este se privilegió la apertura comercial, la especialización productiva y la competencia entre unidades territoriales para atraer mayores flujos de capital. De ello se engendró un sector primario que devanea con los precios internacionales, una industria que resultó debilitada, atrasada tecnológicamente, la cual no ha logrado imponer condiciones en los mercados externos, y un sector terciario con baja generación de valor agregado e innovación, en alguna parte ligado a las prácticas informales e ilegales del extractivismo.

Un capítulo para destacar en este caso es el de la industria cañícola, cuya dinámica depende en buena medida de los subsidios estatales a la producción, las ventajas absolutas en términos de fertilidad del suelo —valle 
geográfico del río Cauca-, el abaratamiento de los costos de captación y disposición final del líquido, y mano de obra no calificada — también barata - proveniente de la población mayoritariamente afrodescendiente de la zona. ${ }^{4}$ Para el caso del Valle del Cauca y en el norte del departamento del Cauca, pese a que su gran infraestructura opaca la pequeña propiedad y las economías campesinas, se habla paralelamente de un fenómeno de «desindustrialización» y de «terciarización» en los últimos diez años, que con la ayuda del cambio climático termina afectando la disposición del líquido.

La tarea aquí pasa por robustecer la desmaterialización a través de incentivos al cambio tecnológico y modelos de ecoeficiencia que redunden en la reducción, el reciclaje y la reutilización del agua. Sin embargo, por ser parte de una política económica de carácter más estructural, el alcance de estas recomendaciones podría ser muy restringido si Colombia no hace bloque con países de similares características a fin de ser más activos en la agenda global sobre el fenómeno, a fin de profundizar en la estrategia interna denominada «logística reversiva». ${ }^{5}$ Es este sentido, el afán reciente de hacer parte de la Organización para la Cooperación y el Desarrollo Económicos (OCDE) debe ser la oportunidad para revisar el rumbo de las reformas de finales del siglo pasado.

El segundo punto que enfrentar, desde la perspectiva de la respuesta, es la importancia de ahondar en materia de gobernanza regional. Para ello, la crisis de la gestión pública ambiental debe servir para propiciar ajustes

\footnotetext{
${ }^{4}$ En este sector también se concentra la producción de biocombustibles. Justamente, la estructura de incentivos comenzó con los procesos de desgravación y de promoción a la inversión de la Ley 788 de 2002. En relación con el impuesto sobre las ventas, la caña de azúcar y el alcohol carburante quedaron exentos en su totalidad. Por su parte, el impuesto a las ventas del fruto de la palma de aceite y del azúcar se redujo de $16 \%$ a $7 \%$. Esta ley estableció también una exención al impuesto global y a la sobretasa al alcohol carburante. Por otro lado, la Ley 1111 de 2006 permitió, en su artículo octavo y a partir del 10 de enero de 2010, la deducción de hasta $40 \%$ del valor de las inversiones que se hicieran en activos fijos reales productivos para el pago del impuesto sobre la renta, influenciando positivamente la inversión agroindustrial.

${ }^{5}$ La logística se conoce como el proceso de planificar, implementar y controlar el flujo y almacenaje de materias primas, productos semielaborados o terminados, y de manejar la información relacionada desde el lugar de origen hasta el lugar de consumo, con el propósito de satisfacer los requerimientos de los clientes. Por su parte, la logística inversa — reverse logistics o inverse logistics - surgió a mediados de la década de 1970 como una orientación hacia el reciclado y reutilización de los desechos. En efecto, a diferencia de la logística, la logística inversa estudia los procesos de recuperación de los productos fuera de uso con objeto de aprovechar el valor que aún pudieran incorporar a través de su reutilización, reciclaje, refabricación o proceder a su adecuada eliminación (Balli, 2012).
} 
entre la oferta y la demanda institucional. Efectivamente, desde el primer ángulo los rasgos de la problemática hacen pensar en cuestiones comunes al diagnóstico de Mark Kleiman y Steven Teles (2006), en cuanto se tendría del lado de la oferta una inadecuada capacidad de penetración, definida como el grado en que el Gobierno es capaz de auscultar al interior de la sociedad y entender su dinámica, en este caso, rompe con el tejido social, porque ciertamente el déficit de información se convierte en el elemento retardatario más importante para el alcance de un desarrollo efectivo de la administración pública (véase cuadro 1). En el espectro de las corporaciones autónomas y del mismo Ministerio del Medio Ambiente no hay un sistema de cuentas ambientales consistente y coherente. Es más, el asunto se vuelve más profundo en el caso del departamento del Cauca, quizás por su juventud, la extensión geográfica a cubrir o el peso institucional de la historia colonial. Por tal motivo, la información que alimenta esta investigación debió ser conseguida por fuera de los medios institucionales, utilizando un sistema de información robusto que consultara la fenomenología de los sistemas socioecológicos sobre el nivel de autonomía y capacidad decisoria.

Luego, una cooperación voluntaria inadecuada puede generar un [212] costo de penetración que resulte prohibitivo. En efecto, de la misma manera que en sociedades desprovistas de confianza en el Gobierno, las fallas del Estado y del mercado generan ingobernabilidad, pero también las fallas de no mercado, relacionadas con la articulación de intereses en el seno de la sociedad civil, que hace que cualquier intervención del Gobierno para solucionar un problema resulte escasa. De esta manera, los sistemas de incentivos — no necesariamente económicos - y una reingeniería a las innovaciones ambientales regionales podrían servir para tejer lazos débiles que dinamicen el encuentro entre actores de distinto pelaje organizacional. Por su parte, la dinámica organizacional propiamente dicha, con arreglos altamente centralizados, con poderes de veto en el sistema político, pueden elevar los costos para la sociedad, mientras que en sistemas descentralizados elevan los costos de la intervención del Gobierno a la hora de corregir fallas de mercado.

Esta parece haber sido la característica de la implementación de las tasas retributivas por contaminación, cuyos resultados alejan a los stakeholders, las cuales podrían actuar como principales y las corporaciones autónomas regionales (CAR) como agentes. De esta forma, la información genera una brecha entre las partes, que de golpe ni siquiera contrarrestan los mecanismos 
de rendiciones de cuentas, percibidas como amañadas y monolíticas (Cortés, 2010), algo paradójico en un modelo de descentralización modernizante que lleva más de veinte años.

Cuadro 1. Problemas y recomendaciones de política ambiental frente a la degradación del agua.

\begin{tabular}{|c|c|c|}
\hline Problema & Causa & Medida \\
\hline $\begin{array}{l}\text { La inadecuada capacidad } \\
\text { de penetración }\end{array}$ & Déficit de información. & $\begin{array}{l}\text { Sistema de información } \\
\text { ambiental regional } \\
\text { Banco de proyectos de origen } \\
\text { comunitario }\end{array}$ \\
\hline $\begin{array}{l}\text { Cooperación voluntaria } \\
\text { inadecuada }\end{array}$ & $\begin{array}{l}\text { Fallas del Estado } \\
\text { y del mercado y fallas } \\
\text { de no mercado }\end{array}$ & $\begin{array}{l}\text { Sistema de incentivos: } \\
\text { reingeniería innovaciones } \\
\text { ambientales regionales } \\
\end{array}$ \\
\hline Dinámica organizacional & $\begin{array}{l}\text { Asimetría información agente- } \\
\text { principal: la asimetría } \\
\text { en la información debilita } \\
\text { la capacidad de los segundos } \\
\text { frente a los primeros que } \\
\text { gozan de la posesión del bien }\end{array}$ & $\begin{array}{l}\text { Sistema de información } \\
\text { ambiental regional }\end{array}$ \\
\hline $\begin{array}{l}\text { Falta de atención de los } \\
\text { votantes }\end{array}$ & Problema de la representación & $\begin{array}{l}\text { Ampliar los mecanismos } \\
\text { de participación en la elección } \\
\text { de los directores } \\
\text { de las corporaciones autónomas } \\
\text { regionales (CAR) } \\
\text { y los proyectos agenciados } \\
\text { por la corporación } \\
\text { Educación ambiental } \\
\text { Rendición de cuentas amplia } \\
\text { e informada }\end{array}$ \\
\hline $\begin{array}{l}\text { La trayectoria de } \\
\text { dependencia de la } \\
\text { hechura de la decisión } \\
\end{array}$ & $\begin{array}{l}\text { Altos costos que involucran } \\
\text { converger al consenso } \\
\text { en un sistema democrático }\end{array}$ & $\begin{array}{l}\text { Inversión en capital humano, } \\
\text { meritocracia, participación } \\
\text { de comunidades de base }\end{array}$ \\
\hline $\begin{array}{l}\text { Competencia para llevar } \\
\text { a cabo tareas específicas }\end{array}$ & $\begin{array}{l}\text { Fallas de coordinación } \\
\text { (internalidades) }\end{array}$ & $\begin{array}{l}\text { Articulación de agendas, } \\
\text { innovaciones institucionales } \\
\text { extendidas }\end{array}$ \\
\hline $\begin{array}{l}\text { Baja cultura } \\
\text { administrativa } \\
\text { Letargo en los } \\
\text { procesos de dirección, } \\
\text { organización y control }\end{array}$ & $\begin{array}{l}\text { Fallas del Estado-problemas } \\
\text { de agencia }\end{array}$ & Meritocracia \\
\hline
\end{tabular}

Fuente: elaboración propia. 
También han operado falencias de atención de los votantes en general: el agua no parece estar en la carpeta fundamental de prioridades de los políticos — quizás más de los burócratas-, pero poco en los electores de la región. Como se sabe, los resultados de una elección son un bien público y la participación concomitante adolece de problemas de free riders, e incluso de ignorancia racional. Así, en un escenario de prácticas clientelares y patrimonialistas, la decisión del votante puede percibirse como marginal y poco trascendental, dejando los costos de la votación a los electores efectivos, los cuales pueden estar cooptados o que ante los costos de la información recurran a la alternativa más cercana. Esto parece generar una especie de crisis de representación que se refleja en los mecanismos de elección de los delegados en los consejos de dirección de las CAR y la limitada gobernabilidad de la gestión pública del agua, de pronto, con mayor evidencia en el caso del departamento del Cauca. Ante esto, es urgente reactivar la educación ambiental, acompañado de estrategias de difusión consistentes en el tiempo. Por ese mismo conducto, revitalizar los mecanismos de rendición de cuentas más allá de un simple conciliábulo de los amigos del director de turno (véase cuadro 1). Con un efectivo capital social externo, podrían funcionar.

Por otro lado, la alta aversión al riesgo, que en un ambiente de asimetrías [214] de información alimenta la fidelidad al pasado y a las decisiones públicas, las cuales dependen más de patrones históricos — trayectoria de dependencia—. Contar con mecanismos amplios de discusión y evaluación multicriterio podría ayudar a quebrar los anclajes administrativos oportunistas e incrementales. A esto hay que sumar la modernización del aparato burocrático y la fidelización de los mecanismos de actividad comunitaria, que pueden ser salidas expeditas al fenómeno.

Finalmente, la competencia para llevar a cabo tareas específicas y la baja cultura administrativa que lleva, entre otras cosas, al letargo en los procesos de dirección, organización y control puede ser atacada con el fortalecimiento de las innovaciones institucionales ambientales, acompañado de procesos meritocráticos que agilicen la formulación, implementación y evaluación de las políticas integradas del agua.

Por el lado de la gobernanza, los resultados no parecen ser robustos (Ostrom, 1999; Anderson y Ostrom, 2008). Para Elinor Ostrom la gobernanza policéntrica consiste en la existencia de múltiples centros que toman decisiones individualmente, los cuales están bajo lineamientos como: límites claros y 
membresía, reglas congruentes, áreas de decisión colectiva, monitoreo, sanciones graduales, mecanismos de resolución de conflictos, reconocimiento del derecho a organizarse, empresas anidadas y desempeño institucional, con lo cual, se espera que el resultado sea una gobernanza policéntrica robusta.

Cuadro 2. Síntesis de los principios de diseño institucional para lograr el gobierno policéntrico.

\begin{tabular}{|c|c|c|c|c|c|c|c|c|c|c|}
\hline Criterio & 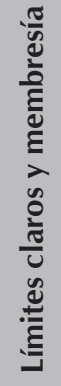 & 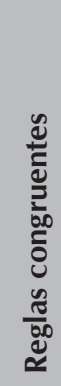 & 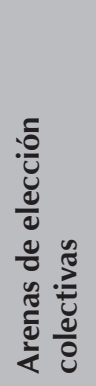 & $\begin{array}{l}\frac{8}{0} \\
\frac{0}{\frac{0}{E}} \\
\frac{0}{2}\end{array}$ & 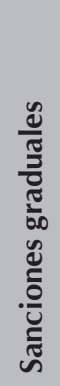 & 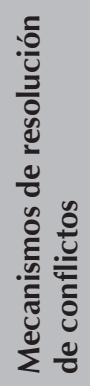 & 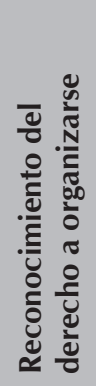 & 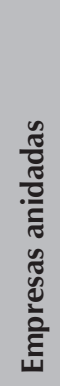 & 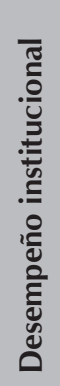 & 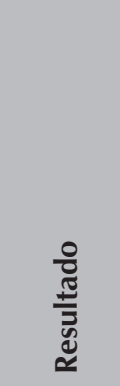 \\
\hline Situación B & Sí & Sí & Sí & Sí & Sí & Sí & Sí & Sí & Sí & Robusto \\
\hline Situación D & Sí & Sí & Sí & Sí & Sí & Débil & Débil & Sí & Sí & Frágil \\
\hline Situación E & Sí & Sí & Débil & Sí & Sí & Sí & $N R$ & No & No & Frágil \\
\hline Situación F & No & $\mathrm{No}$ & No & No & No & No & Débil & No & No & Fracaso \\
\hline Situación G & No & Sí & No & No & No & No & No & No & No & Fracaso \\
\hline Situación H & No & No & No & No & No & Sí & Sí & No & No & Fracaso \\
\hline
\end{tabular}

Fuente: elaborado a partir Ostrom (1999).

Si se retrotrae el planteamiento de la gobernanza policéntrica, se puede ver que la idea de consolidar una gobernanza policéntrica y multinivel sucumbe cuando el sistema de gobernanza regional de agua tiende a fragmentarse de una entidad regional a otra sin lograr anidaciones multiescalares. Justamente, el tipo de organización reticular concentrado en pocos ejes y sin articulaciones en cliques, configura un panorama monocéntrico que, si bien reconoce límites de membresía y arenas de elección colectivas, no plantea sanciones graduales, debilita los sistemas de monitoreo y baja los niveles de desempeño institucional. Con esto se puede afirmar que este sistema de gobernanza débil no llegará a convertirse en un fracaso, porque si bien pululan los problemas de coordinación perviven empresas anidadas, aunque frágilmente aglutinadas. 
De hecho, se puede afirmar que transitan entre la figura de movimiento social — corto plazo - y la de organización capaz de articular entidades variadas de acción colectiva —-mediano plazo — con múltiples estrategias, tipos de actores y capacidades de negociación en el tiempo. En este orden de ideas, habría que fortalecer y direccionar las innovaciones institucionales ambientales, pero en torno a una visión más amplia de cuenca y de una intencionalidad pedagógica generadora de confianza.

\section{Gobernanza y asociacionismo en la cuenca alta del río Cauca $^{6}$}

Si se abstrae espacialmente la forma de los relacionamientos y se intenta cruzar con los modelos económicos de localización, se evidencia un modelo de círculos concéntricos como el de Von Thünen (1826), donde la centralidad varía con la distancia a las autoridades tradicionales y a los grandes núcleos urbanos (Salguero, 2006), es más, se asemeja a uno del tipo centro-periferia, pero donde los miembros de la última tienen bajo poder de conectividad entre ellos.

En esta investigación, el centro aparece conformado por las [216] corporaciones autónomas regionales (CAR) y la periferia por un conjunto de organizaciones donde se destacan algunas de naturaleza civil, otras estatales y algunas de carácter gremial con intereses económicos muy puntuales por ejemplo, Asociación de Cultivadores de Caña de Azúcar de Colombia (Asocaña), Asociación Nacional de Industriales (ANDI)—. La renta política, ambiental y económica parece inmersa en los vínculos de la red, aunque aparenta variar levemente con la coyuntura. Pero a la larga, lo que inquieta no es tanto la eventualidad de los vínculos y la forma de «estrella» que advierte alta concentración del poder, lo que preocupa es la poca conectividad de la periferia, incluso el bajo protagonismo de las innovaciones ambientales regionales - por ejemplo, Corporación Vallecaucana de las Cuencas Hidrográficas en el Medio Ambiente (Corpocuencas) — que desde la década de 1990 iban a ser llamadas a impulsar los engranajes multisectoriales. Esto, a la usanza de los «vínculos débiles», denominados así por Mark Granovetter (2005) en su exploración de la sociología económica y la teoría neoinstitucional.

\footnotetext{
${ }^{6}$ Gobernanza es diferente a gobernabilidad, la primera hace referencia a la capacidad del Gobierno para generar políticas a partir de necesidades, teniendo en cuenta a los diversos actores sociales, políticos y económicos. Por otro lado, la gobernabilidad hace referencia a la capacidad de las instituciones públicas para resolver los desafíos u oportunidades que se le presentan (Mayorga y Córdova, 2007).
} 
No obstante, entre todas estas tendencias generales, la situación entre cada ente territorial resultó cambiante. Por ejemplo, al situarse en el problema de la gobernabilidad, analizándolo desde las autoridades ambientales —oferta institucional— hacia la sociedad civil — demanda—, la brecha que se percibe no es totalmente igual en el departamento del Valle del Cauca, como en el departamento del Cauca (véase mapa 1). ${ }^{7}$

En el primero, el déficit de acercamiento parece pasar, entre otras cosas, por una marca tecnocrática que forjó con su antigüedad la Corporación Autónoma Regional del Valle del Cauca (CVC), fuera de un músculo financiero que le da capacidad de agendar cosas, incluso bajo la égida administrativa «incremental»y algo «oportunista», apartada en ocasiones del estamento societal. En el segundo, una tradición política «gamonalista» que hace que la Corporación Autónoma Regional del Cauca (CRC) distribuya su atención casi que en función de una estructura de castas, donde los grupos indígenas y comunidades negras y algunas asociaciones de base quedan cuasimarginados o en el piso de la pirámide. Sumado a esto, un territorio mucho más vasto, de difícil acceso y con presencia guerrillera, paramilitar y de bandas emergentes habla de la incapacidad del Estado de controlar coercitivamente el territorio; igualmente, menor experiencia gerencial y un aparato burocrático mucho más débil en lo técnico y en la resolución de conflictos, muchos de ellos estructurales y ligados a la lucha ancestral por la tierra.

Del lado de la gobernanza — demanda—, es decir, de la sociedad civil hacia el Estado, una desconfianza que se incrementa conforme aumenta la dispersión geográfica hacia las zonas rurales y en la cual se pronuncia la pobreza (véase gráfica 1). En consecuencia, el departamento del Cauca resulta siendo el más afectado si se revisan los antecedentes esperanzadores de la movilización indígena y campesina de finales de la década de 1990 (Rojas, 2015). No obstante, el rasgo que anuncia este fenómeno es un prototipo de capital social interno, otra vez sectorizado y quizás también homofílico y estratificado por aquello de la herencia colonial (Sinisterra, 2009). Es decir, que despliega confianza al interior del grupo, pero poco hacia el exterior, en una especie de relación endogámica y que de golpe no propicia acciones colectivas de mayor alcance fuera de la coyuntura socioeconómica que a la postre termina ligándose al problema de tierras.

\footnotetext{
${ }^{7}$ En términos administrativos, la cuenca alta del Río Cauca, la segunda fuente hídrica del país, abarca al departamento del Cauca —al suroccidente del país, río arriba- y al departamento del valle del Cauca - más al norte, río abajo-.
} 
Mapa 1. Proyectos e instituciones en la cuenca, según ente territorial.

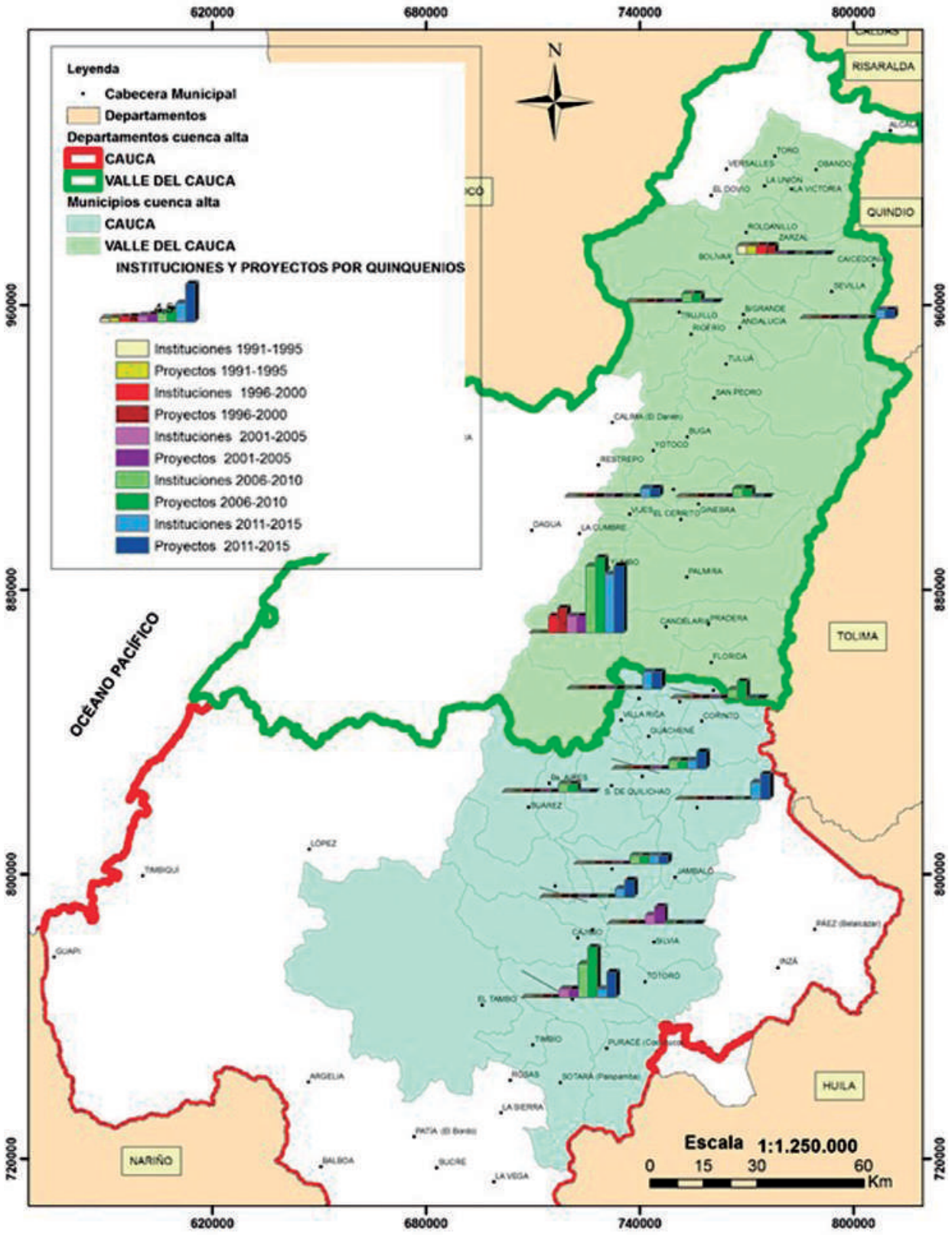

Fuente: elaboración propia a partir de los datos de la encuesta realizada en el marco del proyecto Acción colectiva, cohesión social y asocianismo étnico en el departamento del Cauca, 2016-2017 y el SIG-OT Colombia (s. a.). 
Gráfica 1. Red de gobernanza del agua (restringida). Cuenca alta del río Cauca (1990-2011).

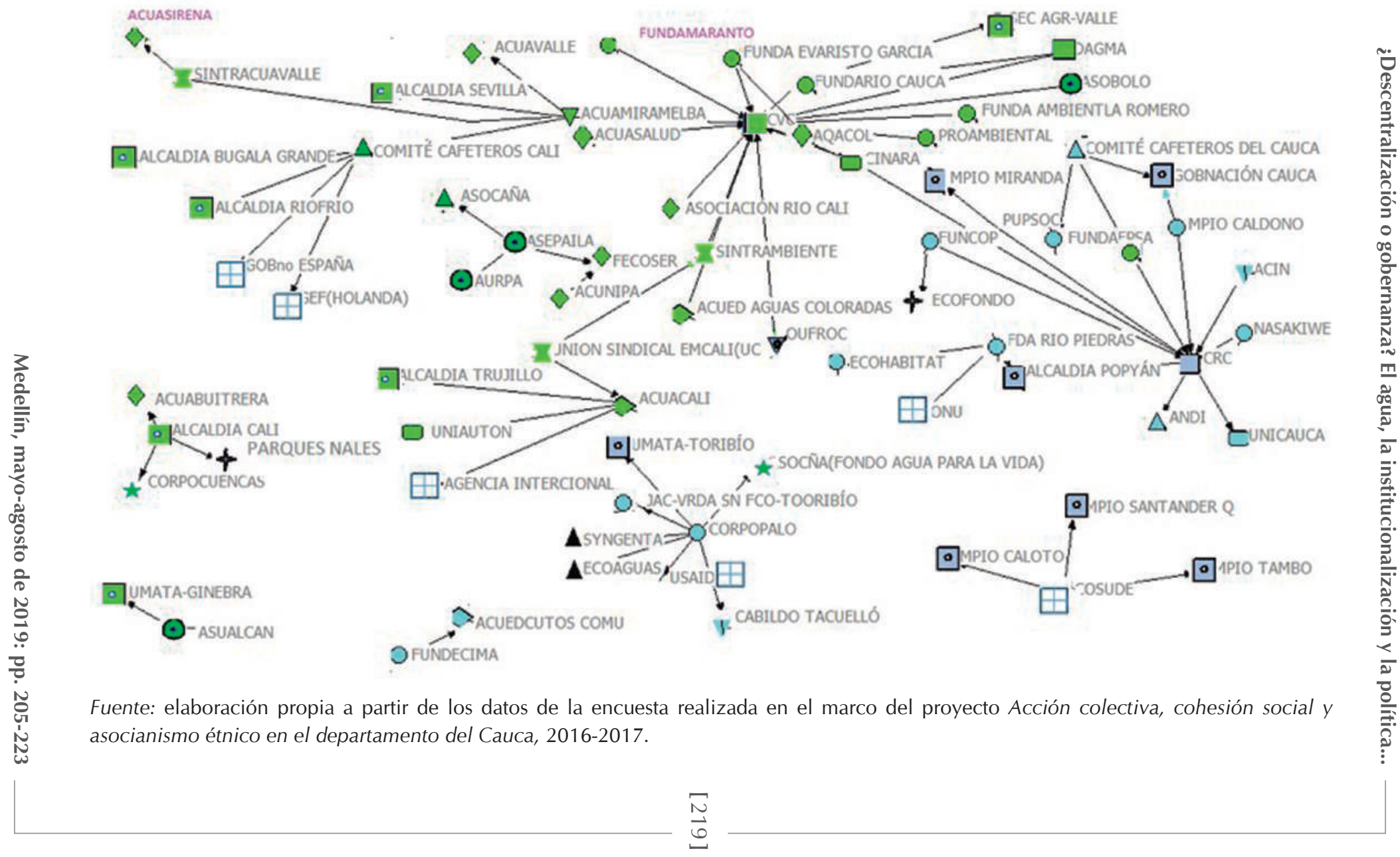


De esta forma, el panorama asociativo de la cuenca, aunque existe, resulta atomizado y propicio para que en medio de este juego de intereses de «suma cero» ${ }^{8}$ sea la tradición y la legalidad la que se imponga, porque, al fin y al cabo, los costos de la información podrían superar los beneficios y optar por la aversión al riesgo. Aun así, desde el ámbito central, el Estado ha intentado sumar nuevos elementos al suministro del líquido apostando a la armonización regional a través de los planes departamentales de aguas (PDA).

\section{Conclusiones. El futuro de la gestión del agua en la cuenca}

Cada vez hay mayor consenso en los círculos del desarrollo en que la escasez de agua y el aumento de la contaminación son, en gran medida, problemas inducidos social y políticamente (Martínez, 2011). En efecto, la crisis del líquido tiene cada vez más que ver con la manera en que nosotros como individuos y como parte de una sociedad administramos el acceso y el control de los recursos hídricos, así como sus beneficios. De hecho, cualquier sistema de gobernanza del agua debe ser capaz de asignar suficiente líquido para garantizar la alimentación y seguridad, pero también ser capaz de apropiar aprendizajes institucionales para redistribuirla en forma eficiente, eficaz, eq-

[220 ] uitativa y legítima. No obstante, un buen arreglo social que despliegue acción colectiva en defensa de esta clase de bienes públicos responde a un proceso complejo que se ve influido por los principios generales de gobernabilidad de un país dado, sus costumbres, tradiciones, sus políticas y acontecimientos geoestratégicos producidos dentro del mismo territorio y de los países vecinos — por ejemplo, un conflicto-, junto a la evolución de la economía global.

El Gobierno nacional estableció la Política de gestión integral del recurso hídrico (Ministerio de Ambiente, 2010), donde formula en líneas gruesas los principios de una gestión encaminada a preservar este recurso en términos de calidad y cantidad, con el ánimo de hacerlo accesible a la población. No obstante, fuera de horadar el ejercicio de gobernabilidad con la desagregación de funciones y responsabilidades en muchas instituciones en su férrea defensa del modelo de descentralización, los ejercicios de planeación del territorio dejan por fuera las aspiraciones de los usuarios y de las organizaciones sociales involucradas en la gestión del recurso. Así entonces, el sector agrícola como

\footnotetext{
${ }^{8}$ En la teoría de juegos, perteneciente a la microeconomía, se denomina suma cero a la interacción entre individuos promovidos por sus intereses, la cual hace que las ganancias o pérdidas de un participante se equilibren con las del otro; es decir, al sumar el total de pérdidas y ganancias en el juego da como resultado cero (Mochón, 2006).
} 
actor determinante no hace uso generalizado de tecnologías eficientes de riego; el sector industrial presiona para que las tasas de uso y retributivas sean cada vez más bajas; las autoridades locales, responsables del tratamiento del agua para potabilizar como de las aguas servidas, aunque parecen preferir pagar los impuestos pigouvianos a operar las plantas de tratamiento de aguas residuales (PTAR), las eluden con el beneplácito de las CAR, las cuales no encuentran incentivo para vigorizarlas. La comunidad en general no exige sus derechos al acceso del agua, ni reivindica el adecuado manejo del recurso una vez utilizado, salvo en periodos de estiaje, donde se adoptan paliativos. Sumado a ello, si se toma el planteamiento de generar una gobernanza policéntrica no se podría consolidar debido a que el sistema de gobernanza regional del agua tiende a fragmentarse de una entidad a otra sin lograr política en común.

Empero de continuar la tendencia y no tomar acciones de largo plazo como las mencionadas arriba, el escenario del cambio climático puede agregar a la conflictividad que se vive en el país desde hace más cincuenta años (Águila, 2016). De hecho, los primeros efectos de este conflicto se han vivido al suroccidente del departamento del Valle del Cauca, por ejemplo, donde las protestas por el agua realizadas por habitantes de Florida y Villagorgona (Candelaria) han desencadenado hechos de violencia con asonadas y heridos en los últimos años (El Tiempo, 2015, marzo 14). Por lo pronto, un hecho que llama profundamente la atención es que en los recientes diálogos de paz entre el Gobierno y las FARC no se contemplen las pugnas por el acceso a los recursos naturales y del agua en particular, como tampoco los acaecidos por actos de terrorismo, como las explosiones de oleoductos, daños a acueductos y tala indiscriminada de bosques para siembra de cultivos ilícitos (SantosCaicedo, 2016).

\section{Referencias bibliográficas}

1. Águila Coghlan, Juan Carlos. (2016). La comunicación del cambio climático: análisis del discurso de los telediarios españoles sobre las cumbres de Cancún y Durban. (Tesis inédita de doctorado). Universidad Complutense de Madrid, Madrid.

2. Anderson, Krister \& Ostrom, Elinor. (2008). Analyzing Decentralized Resource Regimes from a Polycentric Perspective. Policy Sciences, 41 (1), pp. 1-23. https://doi. org/10.1007/s11077-007-9055-6

3. Auty, Richard. (1993). Sustaining Development in Mineral Economies: The Resource Curse Thesis. London: Routledge.

4. Balli, Basilio. (2012). La logística reversa o inversa, aporte al control de devoluciones y residuos en la gestión de la cadena de abastecimiento. Revista de Logística, 5 (18), pp. 28-39. 
5. Colombia. Congreso. Ley 99. (22 de diciembre de 1993). Por la cual se crea el Ministerio del Medio Ambiente, se reordena el Sector Público encargado de la gestión y conservación del medio ambiente y los recursos naturales renovables, se organiza el Sistema Nacional Ambiental, SINA y se dictan otras disposiciones. Recuperado de http://www.secretariasenado.gov.co/senado/basedoc/ley_0099_1993.html

6. Colombia. Congreso. Ley 142. (11 de julio de 1994). Por la cual se establece el régimen de los servicios públicos domiciliarios y se dictan otras disposiciones. Recuperado de http://www.secretariasenado.gov.co/senado/basedoc/ley_0142_1994. html

7. Colombia. Congreso. Ley 788. (27 de diciembre de 2002). Por la cual se expiden normas en materia tributaria y penal del orden nacional y territorial; y se dictan otras disposiciones. Recuperado de http://www.secretariasenado.gov.co/senado/basedoc/ ley_0788_2002.html

8. Colombia. Congreso. Ley 1111. (27 de diciembre de 2006). Por la cual se modifica el estatuto tributario de los impuestos administrados por la Dirección de Impuestos y Aduanas Nacionales. Recuperado de http://www.secretariasenado.gov. co/senado/basedoc/ley_1111_2006.html

9. Colombia. Congreso. Ley 1151. (24 de julio de 2007). Por la cual se expide el Plan Nacional de Desarrollo 2006-2010. Recuperado de http://www.secretariasenado. gov.co/senado/basedoc/ley_1151_2007.html

10. Colombia. Departamento Nacional de Planeación. Documento Conpes [222] 3383. (10 de octubre de 2005). Plan de desarrollo del sector de acueducto y alcantarillado. Recuperado de https://colaboracion.dnp.gov.co/CDT/Conpes/ Econ $\%$ C3\%B3micos/3383.pdf

11, Colombia. Departamento Nacional de Planeación. Documento Conpes 3463. (12 de marzo de 2007). Planes departamentales de agua y saneamiento para el manejo empresarial de los servicios de acueducto, alcantarillado y aseo. Recuperado de https://colaboracion.dnp.gov.co/CDT/Conpes/Econ\%C3\%B3micos/3463.pdf

12. Colombia. Departamento Nacional de Planeación. Documento Conpes 3624. (20 de noviembre de 2009). Programa para el saneamiento, manejo y recuperación ambiental de la cuenca alta del río Cauca. Recuperado de https://colaboracion.dnp. gov.co/CDT/Conpes/Econ\%C3\%B3micos/3624.pdf

13. Contraloría General de la República. (2011). Evaluación de la política de planes departamentales para el manejo empresarial de los servicios de agua y saneamiento -PDA-. Recuperado de https://www.contraloria.gov.co/documents/20181/465179/ Evaluacion-Politica-Planes-Dptales-Manejo-Empresarial-Servicios-Agua-ySaneamiento-PDA.pdf/b639baaf-bf0e-4af9-a93e-49aab6b69955

14. Cortés Landázury, Raúl. (2010). La maldición de los comunes o la transgresión de los privados. Revista Observatorio Empresarial, 2, pp. 8-94.

15. El Tiempo. (2015, marzo 14). Dos pueblos del Valle en «guerra» por acceso al agua. Recuperado de https://www.eltiempo.com/archivo/documento/CMS-15399381 
¿Descentralización o gobernanza? El agua, la institucionalización y la política...

16. Foro Nacional Ambiental. (s. a.). Política y legislación ambiental. Recuperado de https://www.foronacionalambiental.org.co/nuestros-temas/politica-ambientalnacional/

17. Granovetter, Mark. (2005). The Impact of Social Structure on Economic Outcomes. Journal of Economic Perspectives, 19 (1), pp. 33-50. https://doi. org/10.1257/0895330053147958

18. Inglehart, Ronald \& Abramson, Paul. (1994). Economic Security and Value Change. The American Political Science Review, 88 (2), pp. 336-354. https://doi. org/10.2307/2944708

19. Kleiman, Mark \& Teles, Steven. (2006). Market and Non-Market Failures. In: Moran, Michael; Rein, Martin \& Goodin, Robert E. (eds.). The Oxford Handbook of Public Policy (pp. 624-650). New York: Oxford University.

20. Martínez Allier, Joan. (2011). De la economía ecológica al ecologismo popular. Barcelona: Icaria.

21. Mayorga, Fernando y Córdova, Eduardo. (2007) Gobernabilidad y gobernanza en América Latina. Working Paper NCCR Norte-Sur IP8, Ginebra.

22. Ministerio de Ambiente, Vivienda y Desarrollo Territorial. (2010). Política nacional para la gestión integral del recurso hídrico. Bogotá, D. C.: Ministerio de Ambiente.

23. Mochón, Francisco. (2006). Principios de economía. Madrid: McGraw-Hill.

24. Naciones Unidas. Asamblea General. Resolución 64/292. (28 de julio de 2010). El derecho humano al agua y el saneamiento. Recuperado de http://daccess-ods. un.org/access.nsf/GetFile?OpenAgent \&DS =A/RES/64/292\&Lang =S\&Type = DOC

25. O'Connor, James. (2001). Causas naturales. Ensayos de marxismo ecológico. México, D. F.: Siglo xxı.

26. Ostrom, Elinor. (1999). Governing the Commons. Cambridge: Cambridge University.

27. Rojas, Esneider. (2015). El movimiento campesino en el Cauca: organización y lucha territorial por el reconocimiento como sujetos de derechos. Controversia, 205, pp. 99-124.

28. Salguero, Jorge. (2006). Enfoque sobre algunas teorías del desarrollo regional. Sociedad de Geográfica de Colombia. Academia de Ciencias Geográficas. Recuperado de http://www.economia.unam.mx/academia/inae/pdf/inae5/515.pdf

29. Santos-Caicedo, José. (2016). Conflictos por el uso del suelo: territorios indígenas y afrodescendientes. Bitácora, 26 (2), pp. 87-89. https://doi.org/10.15446/ bitacora.v26n2.59294

30. Sinisterra, Mónica. (2009) Dependencia de la historia en la determinación del capital social, herencia colonial y cambio institucional: el caso caucano. Cuadernos de Economía, 28 (51), pp. 37-74.

31. Sistema de Información Geográfica para el Ordenamiento Territorial (SIG-OT) Colombia. (s. a.). Recuperado de http://sigotvg.igac.gov.co:8080/ 